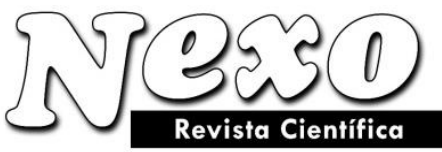

ISSN-E 1995-9516

Universidad Nacional de Ingeniería COPYRIGHT @ (UNI). TODOS LOS DERECHOS RESERVADOS http://revistas.uni.edu.ni/index.php/Nexo https://doi.org/10.5377/nexo.v34i02.11556

\title{
Hybrid DTC strategy based on predictive control with optimization of the PI controller parameters for TPIM drives
}

\section{Estrategia DTC híbrida basada en control predictivo con optimización de los parámetros del controlador PI para unidades TPIM}

\author{
Mehdi Ahmadi Taleshian', Mahmood Ghanbari ${ }^{1, *}$, Seyed Mehdi Rakhtala ${ }^{2}$ \\ ${ }^{1}$ Department of Electrical Engineering, Gorgan Branch, Islamic Azad University, \\ Gorgan, Iran. \\ ${ }^{2}$ Electrical Engineering Department, Golestan University, Gorgan, Iran. \\ * ghanbari@gorganiau.ac.ir
}

(recibido/received: 21 -eneros-2021; aceptado/accepted: 15-mayo-2021)

\begin{abstract}
In this paper, a novel hybrid Direct Torque Control (DTC) strategy based on predictive control with optimization of the Proportional-Integral (PI) controller to improve overall performances of Three-Phase Induction Machine (TPIM) drives is proposed. The presented control technique has contained merits of the DTC method such as fast dynamic response, simple structure, less dependence to machine parameters and merits of vector control method such as high accuracy. Furthermore, a hybrid DTC method with optimal voltage vectors is presented. In the proposed control system, Genetic Algorithm (GA) is employed to obtain optimal values of the PI controller parameters. Finally, simulation results under the presented control strategy showed good performances of this method in comparison with DTC and vector control techniques.
\end{abstract}

Keywords: Hybrid direct torque control, Optimization of PI controller, Predictive control, Three-phase induction machine, Genetic algorithm.

\section{RESUMEN}

En este artículo, se propone una nueva estrategia híbrida de control directo de par (DTC) basada en el control predictivo con optimización del controlador proporcional-integral (PI) para mejorar el rendimiento general de los accionamientos de la máquina de inducción trifásica (TPIM). La técnica de control presentada contiene ventajas del método DTC como respuesta dinámica rápida, estructura simple, menor dependencia de los parámetros de la máquina y ventajas del método de control vectorial como alta precisión. Además, se presenta específicamente un método DTC híbrido con vectores de voltaje óptimos. En el sistema de control propuesto, se utiliza un algoritmo genético (GA) para obtener valores óptimos de los parámetros del controlador PI. Finalmente, los resultados de la simulación bajo la estrategia de control presentada muestran buenos resultados de este método en comparación con las técnicas de control de vectores y DTC. 
Palabras clave: Híbrido de par directo control, Optimización del controlador PI, Control predictivo, Máquina de inducción trifásica, Algoritmo genético.

\section{INTRODUCTION}

Direct Torque Control (DTC) methods are two common control approaches for machine drives. ThreePhase Induction Machines (TPIMs) are so popular due to their significant advantages like simplicity, high reliability and low cost (Tabasian et al, 2020; Tarchala and Orłowska-Kowalska, 2018). These machines are found in different industrial applications such as pumps, electric vehicles, wind turbines, and so on. For some industrial applications, control of a drive system with high performance is a challenging issue. Vector control or Field-Oriented Control (FOC) methods and in industry (Jannati et al, 2014; Liu and Luo, 2017). In general, vector control methods are complex methods. In addition, these methods depend on machine parameters and have low dynamic response compared to DTC methods (de Almeida et al, 2017; Jannati et al, 2017).

DTC method is very popular control strategy due to its simple structure, low cost, and fast dynamic response for TPIM drive systems. In DTC method, appropriate voltage vectors are selected based on a predefined switching table using two-level hysteresis controllers for the stator flux and three-level hysteresis controllers for the torque (Kumar et al, 2017). In spite of these advantages, this method suffers from high torque and flux ripples, as well as variable switching frequency. In recent years, different schemes have been proposed to enhance the performance of the conventional DTC method (Ismail et al, 2017; Jidin et al, 2017; Jannati et al, 2013).

Moreover, predictive control methods are known as efficient control methods for linear and nonlinear systems in different applications such as drive systems. In predictive control methods, the next state of the control components is predicted based on the system model. In predictive DTC, the idea of the conventional DTC method is used. The main focus of this strategy is on prediction of future values of flux and torque. Predictive DTC method including two steps: prediction and optimization. In this method, the optimal voltages are obtained by minimizing the objective function such as flux error or torque error or combination of these errors. This approach contains some advantages such as lower torque ripples, lower flux ripples, and lower losses compared to the conventional DTC method (Bolgnani et al, 2008).

Recently, different approaches based on predictive DTC have been proposed to overcome the conventional DTC problems. In (Ouhrouche et al, 2016), predictive DTC method using a predictive switching table for TPIM drives along with a Kalman filter to estimate the stator flux was presented. In the research by Mossa et al, predictive DTC method for TPIM drives using reactive power was suggested (Mossa and Bolgnani, 2017). In the study by Beerten et al, a method for controlling the velocity of TPIM along with compensating for delay based on direct torque-predictive control method was proposed (Beerten et al, 2009). A predictive DTC technique based on discrete time model for TPIM drives was investigated (Miranda et al, 2009). Also, the predictive DTC strategies using space vector modulation and three-level inverter have been introduced, respectively (Amiri et al, 2018; Papafotiou et al, 2008).

A predictive DTC method using fuzzy logic was presented (Berzoy et al, 2017). Even though the aforementioned methods can enhance the performance of the conventional predictive DTC, the main focus of these papers is on the steady state performance of the drive system. Moreover, these methods have high computational complexity and depend on machine parameters.

In industrial applications, hybrid systems are normally used. A hybrid system involves a continuous time system controlled by a discrete time controller with a limited number of states. In drive systems, the machine can be considered as a continuous time system and the inverter can be considered as a discrete time system. 
Hybrid control system is used to control a hybrid system. In hybrid control systems for electric drives, the inverter model that normally ignored in the control system is considered. In these systems, inverter switching states are considered as a control variable (Lin-Shi et al, 2007; Navardi et al, 2018).

One of the popular controllers used in drive systems is Proportional-Integral (PI) controller. This controller can be used in a wide range of speed because of its simple structure and good performance (Ramahlingam et al, 2016). The performance of this controller depends on two parameters: proportional and integral parameters. Different approaches have been proposed to tune PI parameters such as Ziegler-Nichols method. However, in this method accurate values of machine parameters are needed. As an alternative method, optimization methods can be utilized to design PI parameters. Genetic Algorithm (GA) is widely used to tune PI parameters in drive systems. This algorithm has an advantage over other optimization algorithms such as its fast convergence and acceptable accuracy (Jannati et al, 2014; Demir and Vural, 2018).

This paper proposes a hybrid DTC strategy for TPIM drives based on predictive control along with optimization of the PI controller using GA. The proposed method is obtained by combining a DTC method with a predictive control method. Simulation results indicate that the proposed control method has better performances in both transient and steady state compared to the conventional DTC. Furthermore, the results show that the proposed control method has simple structure and better transient performance compared to the conventional vector control strategy. In addition, the results indicate the effect of the PI controller optimization in the performance of the proposed hybrid DTC strategy.

This paper is organized as follows: after introduction in Section 1, the conventional vector control method for TPIM drives is presented in section 2. In this section, the vector control method based on stator FOC method is explained shortly. The conventional DTC for TPIM drives is shown in Section 3. Section 4 presents the proposed hybrid DTC based on predictive control and the optimization of the PI controller using GA is explained in Section 5. In Section 6, the MATLAB simulation results are given.

In Section 2, data and methodology are described and the main results of the simulations are presented in section 3 and the conclusions are drawn in Section 4.

\section{DATA AND METHODOLOGY}

Vector control or FOC method is one of the most common control approaches for TPIM drives. This control strategy is based on the dynamic equations of TPIM. In other words, this control method has good transient and steady state responses. This control strategy can control the flux and torque components independently by suitable orientation of the stator flux or rotor flux or magnetizing flux (Vas, 1998).

The way of calculation of the flux determines the type of vector control method which can be direct or indirect. Generally, in the direct method the flux is measured using a Hall-effect sensor, and in the indirect method the flux is determined based on the machine equations. The block diagram of the conventional indirect stator FOC for TPIM drives is shown in Figure 1.

In Figure 1, $\left|\lambda_{s}\right|$ is the stator flux amplitude, $\omega_{s}$ is the stator angular speed, $T_{e}$ is the machine torque, $\omega_{r}$ is the machine speed, $\mathrm{v}_{\mathrm{ds}}, \mathrm{v}_{\mathrm{qs}}, \mathrm{i}_{\mathrm{ds}}, \mathrm{i}_{\mathrm{qs}}$ are the stator voltages and currents in the rotating reference frame, $\mathrm{v}_{\mathrm{sds}}, \mathrm{v}_{\mathrm{sqs}}$, $i_{\text {sds }}, i_{\text {sqs }}$ are the stator voltages and currents in the stationary reference frame, $S_{a}, S_{b}, S_{c}$ are the switching states, and $\theta_{\mathrm{s}}$ is the stator flux angle. 


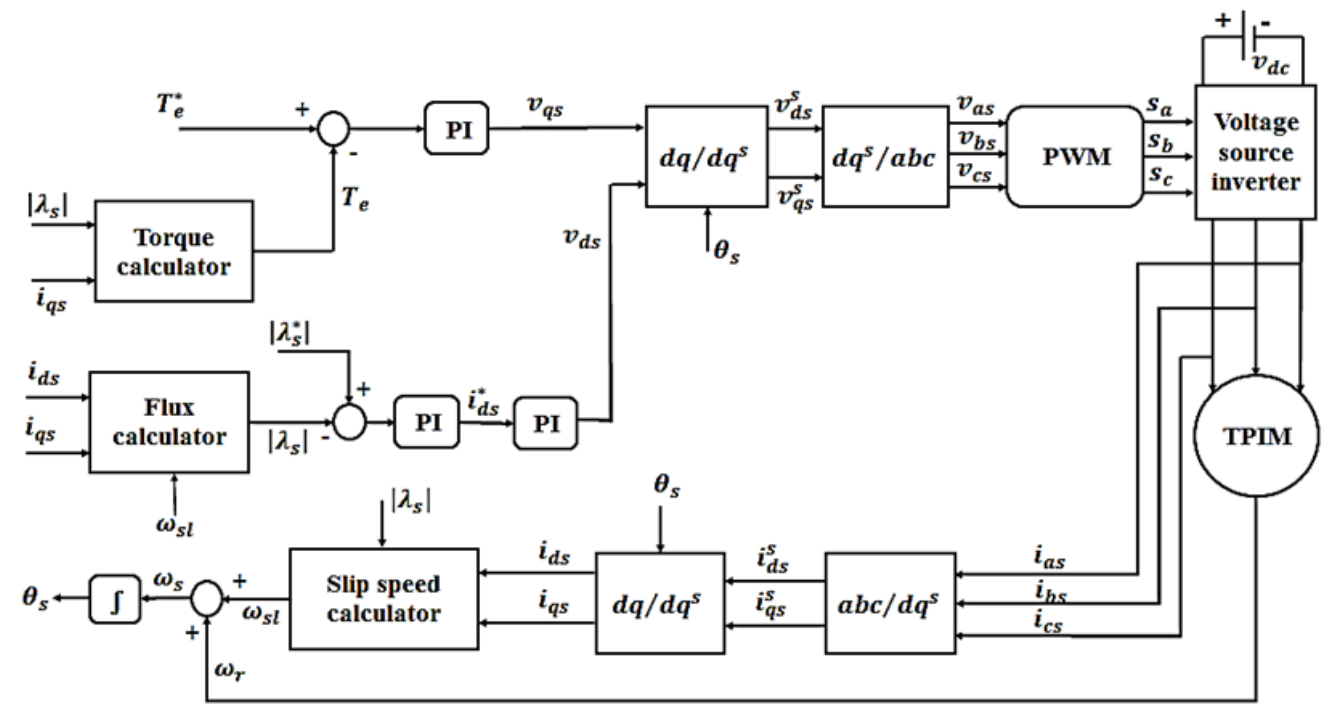

Figure 1. Block diagram of the conventional indirect stator FOC for TPIM drives

Takahashi in the early 1980s introduced the DTC strategy. This control system has a simple algorithm, fast dynamic response and its implementation is easier compared to vector control approaches. two hysteresis comparators (two-level hysteresis comparator for stator flux components and a three-level hysteresis comparator for torque components), flux and torque calculators, a switching table, and a voltage source inverter is used in the conventional DTC method. In this control system, independent control of the stator flux and torque is done by selecting suitable voltage vectors from the switching table (see Table 1) and according to the maintenance of the stator flux and torque errors in the hysterical bands.

The main disadvantages of this control method are including variable switching frequency, high torque ripples, and the problem of the flux drop at low speed. The block diagram of the conventional DTC for TPIM drives is shown in Figure 2.

Table 1. Selecting suitable voltage vectors from the switching table

\begin{tabular}{|c|c|c|c|c|c|c|c|}
\hline \multirow{3}{*}{$\lambda_{\mathrm{s}}^{\mathrm{h}}$} & \multirow{2}{*}{$\mathrm{T}_{\mathrm{e}}^{\mathrm{h}}$} & \multicolumn{6}{|c|}{ sector } \\
\cline { 3 - 8 } & & & 2 & 3 & 4 & 5 & 6 \\
\hline \multirow{3}{*}{-1} & +1 & $010\left(\mathrm{v}_{3}\right)$ & $011\left(\mathrm{v}_{4}\right)$ & $001\left(\mathrm{v}_{5}\right)$ & $101\left(\mathrm{v}_{6}\right)$ & $100\left(\mathrm{v}_{1}\right)$ & $110\left(\mathrm{v}_{2}\right)$ \\
\cline { 2 - 8 } & 0 & $111\left(\mathrm{v}_{7}\right)$ & $000\left(\mathrm{v}_{0}\right)$ & $111\left(\mathrm{v}_{7}\right)$ & $000\left(\mathrm{v}_{0}\right)$ & $111\left(\mathrm{v}_{7}\right)$ & $000\left(\mathrm{v}_{0}\right)$ \\
\cline { 2 - 8 } & -1 & $001\left(\mathrm{v}_{5}\right)$ & $101\left(\mathrm{v}_{6}\right)$ & $100\left(\mathrm{v}_{1}\right)$ & $110\left(\mathrm{v}_{2}\right)$ & $010\left(\mathrm{v}_{3}\right)$ & $011\left(\mathrm{v}_{4}\right)$ \\
\hline \multirow{3}{*}{+1} & +1 & $110\left(\mathrm{v}_{2}\right)$ & $010\left(\mathrm{v}_{3}\right)$ & $011\left(\mathrm{v}_{4}\right)$ & $001\left(\mathrm{v}_{5}\right)$ & $101\left(\mathrm{v}_{6}\right)$ & $100\left(\mathrm{v}_{1}\right)$ \\
\cline { 2 - 8 } & 0 & $000\left(\mathrm{v}_{0}\right)$ & $111\left(\mathrm{v}_{7}\right)$ & $000\left(\mathrm{v}_{0}\right)$ & $111\left(\mathrm{v}_{7}\right)$ & $000\left(\mathrm{v}_{0}\right)$ & $111\left(\mathrm{v}_{7}\right)$ \\
\cline { 2 - 8 } & -1 & $101\left(\mathrm{v}_{6}\right)$ & $100\left(\mathrm{v}_{1}\right)$ & $110\left(\mathrm{v}_{2}\right)$ & $010\left(\mathrm{v}_{3}\right)$ & $011\left(\mathrm{v}_{4}\right)$ & $001\left(\mathrm{v}_{5}\right)$ \\
\hline
\end{tabular}




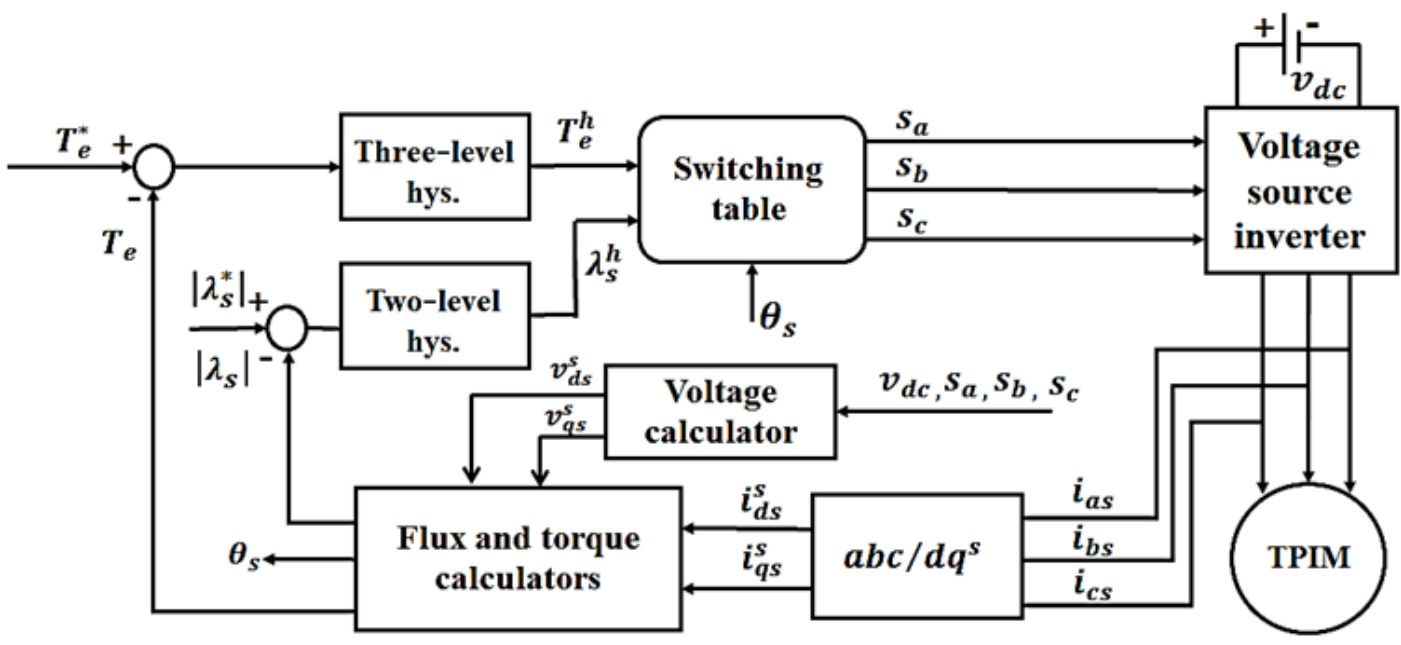

Figure 2. Block diagram of the conventional DTC for TPIM drives

The proposed hybrid DTC strategy based on predictive control is presented. The vector diagrams of the rotor and stator fluxes in different reference frames can be shown in Figure 3.

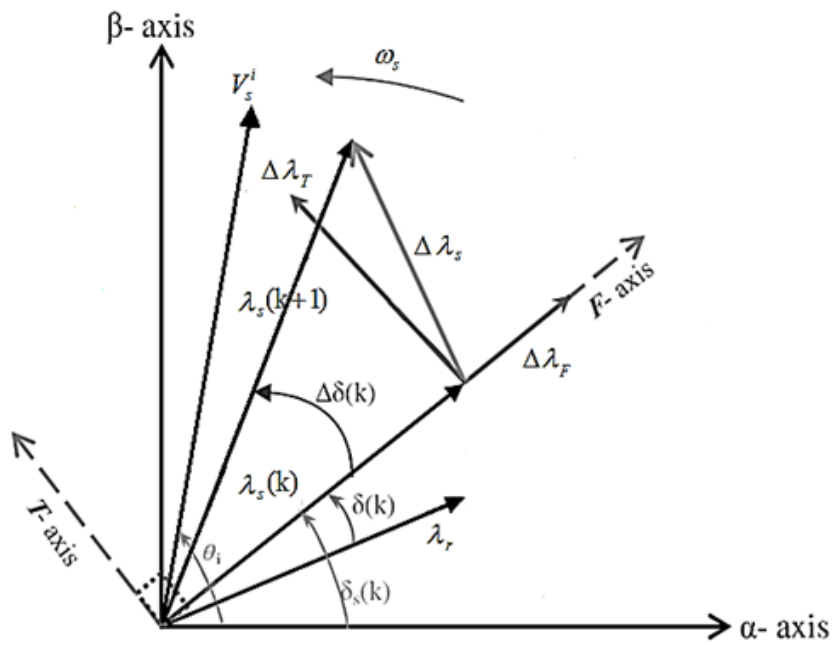

Figure 3. Vector diagrams of the rotor and stator fluxes in different reference frames

The stator flux variations of a TPIM can be written as (1) and (2):

$$
\begin{aligned}
& \Delta \vec{\lambda}_{\mathrm{s}}=\overrightarrow{\mathrm{V}}_{\mathrm{s}} \mathrm{T}_{\mathrm{s}} \rightarrow \vec{\lambda}_{\mathrm{s}}(\mathrm{k}+1)=\vec{\lambda}_{\mathrm{s}}(\mathrm{k})+\left(\overrightarrow{\mathrm{V}}_{\mathrm{s}}(\mathrm{k})\right) \mathrm{T}_{\mathrm{s}} \\
& \Delta \vec{\lambda}_{\mathrm{s}}(\mathrm{k}+1)=\vec{\lambda}_{\mathrm{s}}(\mathrm{k}+1)-\vec{\lambda}_{\mathrm{s}}(\mathrm{k})
\end{aligned}
$$

Where, $\Delta$ is very small variations. Moreover, $\vec{\lambda}_{s}(\mathrm{k})$ and $\mathrm{T}_{\mathrm{s}}$ are the stator flux vector at the $k^{\text {th }}$ time and sampling time, respectively. According to Figure 3, the stator flux variations can be written in $F / T$ reference frame as (3):

$$
\Delta \vec{\lambda}_{\mathrm{s}}(\mathrm{k}+1)=\Delta \vec{\lambda}_{\mathrm{F}}(\mathrm{k}+1)+\mathrm{j} \Delta \vec{\lambda}_{\mathrm{T}}(\mathrm{k}+1)
$$

In DTC method, the sampling time is selected very small. Thus, based on Figure $3, \Delta \delta(k+1)$ with a reasonable estimation can be written as: 


$$
\sin (\Delta \delta(\mathrm{k}+1)) \cong \frac{\Delta \vec{\lambda}_{\mathrm{T}}(\mathrm{k}+1)}{\left|\vec{\lambda}_{\mathrm{s}}(\mathrm{k}+1)\right|} \rightarrow \Delta \delta(\mathrm{k}+1) \cong \frac{\Delta \vec{\lambda}_{\mathrm{T}}(\mathrm{k}+1)}{\left|\vec{\lambda}_{\mathrm{s}}(\mathrm{k}+1)\right|}
$$

According to Figure 3 and equation (4), the stator flux variations in $F / T$ reference frame can be written as (5) and (6):

$$
\begin{aligned}
& \Delta \vec{\lambda}_{\mathrm{F}}(\mathrm{k}+1) \cong\left|\vec{\lambda}_{\mathrm{s}}(\mathrm{k}+1)\right|-\left|\vec{\lambda}_{\mathrm{s}}(\mathrm{k})\right| \\
& \Delta \vec{\lambda}_{\mathrm{T}}(\mathrm{k}+1) \cong\left|\vec{\lambda}_{\mathrm{s}}(\mathrm{k}+1)\right| \Delta \delta(\mathrm{k}+1) \rightarrow \Delta \lambda_{\mathrm{T}} \cong\left|\lambda_{\mathrm{s}}\right| \Delta \delta
\end{aligned}
$$

The torque variations of TPIM can be expressed by (Vaez-Zadeh and Jalali, 2007):

$$
\Delta \mathrm{T}_{\mathrm{e}}=\mathrm{k} \Delta \delta
$$

Where,

$$
\mathrm{k}=\frac{3}{2} \frac{\text { pole }}{2} \frac{\mathrm{M}}{\sigma \mathrm{L}_{\mathrm{s}} \mathrm{L}_{\mathrm{r}}}\left|\lambda_{\mathrm{s}}\right|\left|\lambda_{\mathrm{r}}\right| \cos \delta
$$

In (8), $\left|\lambda_{\mathrm{r}}\right|$ is the rotor flux amplitude, $\mathrm{L}_{\mathrm{s}}, \mathrm{L}_{\mathrm{r}}$, and $M$ are the stator and rotor self and mutual inductances. As $\left|\lambda_{s}\right|$ is a constant value, from (6) and (7) it is conclude that the variations of the stator T-axis flux can be controlled by the variations of the torque $\left(\Delta \lambda_{\mathrm{T}} \propto \Delta \mathrm{T}_{\mathrm{e}}\right)$.

The stator voltage vector $\left(\overrightarrow{\mathrm{V}}_{\mathrm{s}}^{\mathrm{i}}\right)$ based on Figure 3, can be divided into two components as (9):

$$
\vec{V}_{\mathrm{S}}^{\mathrm{i}}(\mathrm{k}+1)=\mathrm{V}_{\mathrm{F}}^{\mathrm{i}}+\mathrm{j} \mathrm{V}_{\mathrm{T}}^{\mathrm{i}}
$$

Considering (1)-(9), the objective function to obtain the optimal voltage vectors can be defined as:

$$
M=M_{F}+M_{T}
$$

Where,

$$
\begin{aligned}
& \mathrm{M}_{\mathrm{F}}=\left(\Delta \lambda_{\mathrm{F}}(\mathrm{k}+1)-\mathrm{V}_{\mathrm{F}}^{\mathrm{i}} \mathrm{T}_{\mathrm{s}}\right)^{2} \\
& \mathrm{M}_{\mathrm{T}}=\left(\Delta \lambda_{\mathrm{T}}(\mathrm{k}+1)-\mathrm{V}_{\mathrm{T}}^{\mathrm{i}} \mathrm{T}_{\mathrm{s}}\right)^{2}
\end{aligned}
$$

In (11) and (12), $\Delta \lambda_{F}(k+1)$ and $\Delta \lambda_{T}(k+1)$ are obtained from the following (13) and (14) equations:

$$
\begin{aligned}
& \Delta \lambda_{\mathrm{F}}(\mathrm{k}+1)=\left|\lambda_{\mathrm{S}}^{*}(\mathrm{k}+1)\right|-\left|\lambda_{\mathrm{s}}(\mathrm{k})\right| \\
& \Delta \lambda_{\mathrm{T}}(\mathrm{k}+1)=\left|\lambda_{\mathrm{s}}^{*}(\mathrm{k}+1)\right| \Delta \delta^{*}(\mathrm{k}+1)=\left|\lambda_{\mathrm{s}}^{*}(\mathrm{k}+1)\right| \frac{\mathrm{T}_{\mathrm{e}}^{*}(\mathrm{k}+1)-\mathrm{T}_{\mathrm{e}}(\mathrm{k})}{\mathrm{k}}
\end{aligned}
$$

In according to equation (9), the optimal voltage vectors can be obtained by minimization of the objective function as given in (10)-(14). In according to equations (1)-(14), the block diagram of the proposed hybrid DTC strategy based on predictive control can be shown in Figure 4. 


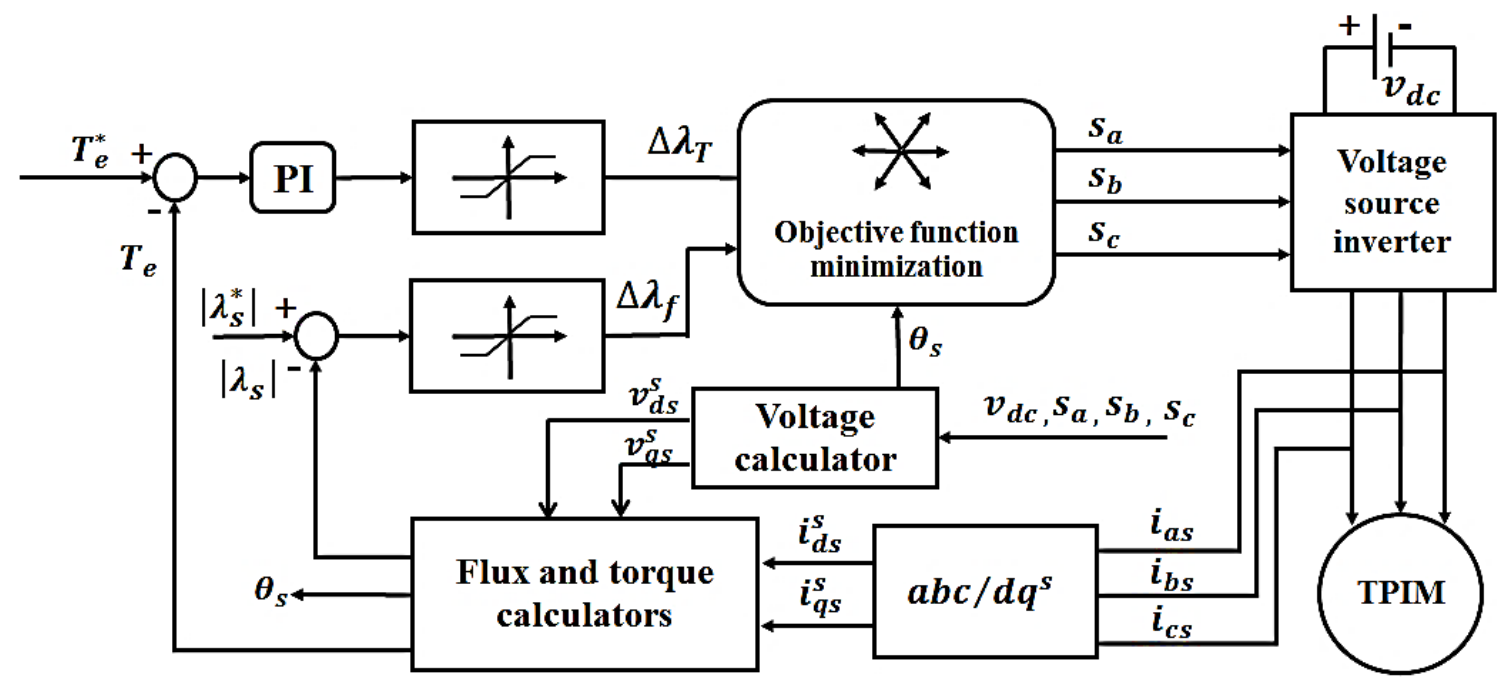

Figure 4. Block diagram of the proposed hybrid DTC strategy based on predictive control

As shown in Figure 4, the variations of the stator T-axis flux are obtained using the torque PI controller. PI controller parameters are very effective in the performance of the proposed control system. In this paper, GA is used to obtain optimal values of the torque PI controller parameters.

Proportional and integral coefficients of PI controllers are often specified by trial and error process. Over the past a few years, different strategies have been developed to obtain the optimum parameters for PI controllers. GA proposed by John Holland is successfully used to solve PI controller optimization problems.

In addition, GA is based on Darwin's evolution theory. In this method, the responses of a population are utilized to produce the next population. In this algorithm, the new population is better than the previous population. Choosing some responses from among the whole responses to generate new responses is according to their popularity. This continues until accomplishment the pre-determined condition.

Objective function is required to calculate the overall responses for each of the sets of PI parameters. The objective function to obtain the optimal values of the PI controller is considered as equation (15):

$$
\text { Objective function }=\int_{0}^{t} e^{2}(t) d t=\int_{0}^{t}\left(T_{e}^{*}-T_{e}\right)^{2} d t
$$

Furthermore, the proportional and integral coefficients can be obtained by minimizing the objective function. The initial populations, crossover probability, generation, and mutation probability used in GA are summarized in Table 2.

Table 2. The parameters of GA

\begin{tabular}{|c|c|c|c|}
\hline Initial populations & Crossover probability & Generation & Mutation probability \\
\hline 40 & 0.6 & 50 & 0.2 \\
\hline
\end{tabular}

Moreover, the off-line results of the optimized values of the PI controller parameters are given in Table 3.

Table 3. The optimized values of the PI controller parameters

\begin{tabular}{|c|c|}
\hline Proportional coefficient & Integral coefficient \\
\hline 50 & 0.3 \\
\hline
\end{tabular}




\section{RESULTS AND DISCUSSIONS}

In this section, the MATLAB simulation results for evaluating the performance of the proposed controller are presented. To compare the proposed method with other controllers, the simulation results of the conventional vector control and DTC methods are also presented. Vector control method, DTC method, and the proposed control method are simulated based on Figures 1, 2, and 4, respectively. The parameters of Three-Phase Induction Machines (TPIM) are given in Table 4.

Table 4. The parameters of TPIM

\begin{tabular}{|c|c|c|c|c|c|c|c|c|}
\hline $\begin{array}{c}\text { Rated } \\
\text { power }\end{array}$ & $\begin{array}{c}\text { Rated } \\
\text { voltage }\end{array}$ & Frequency & $\begin{array}{c}\text { Rated } \\
\text { speed }\end{array}$ & $\begin{array}{c}\text { Number of } \\
\text { pole pairs }\end{array}$ & $\begin{array}{c}\text { Stator } \\
\text { resistance }\end{array}$ & $\begin{array}{c}\text { Rotor } \\
\text { resistance }\end{array}$ & $\begin{array}{c}\text { Stator and } \\
\text { rotor self- } \\
\text { inductances }\end{array}$ & $\begin{array}{c}\text { Mutual } \\
\text { inductance }\end{array}$ \\
\hline $2.5 \mathrm{~kW}$ & $220 \mathrm{~V}$ & $50 \mathrm{~Hz}$ & $1420 \mathrm{rpm}$ & 2 & $3.66 \Omega$ & $1.8 \Omega$ & $0.312 \mathrm{H}$ & $0.302 \mathrm{H}$ \\
\hline
\end{tabular}

Furthermore, the simulation results of the vector control strategy, DTC method, and the proposed control strategy with GA are shown in Figure 5 and 6. Figure 5 shows the simulation results of the flux response and Figure 6 shows the simulation results of the torque response). In Figure 5 and Figure 6 , the reference stator flux is set to $0.6 \mathrm{wb}$. Moreover, the reference torque changes from $2 \mathrm{Nm}$ to $-2 \mathrm{Nm}$ at $\mathrm{t}=0.1 \mathrm{~s}$.
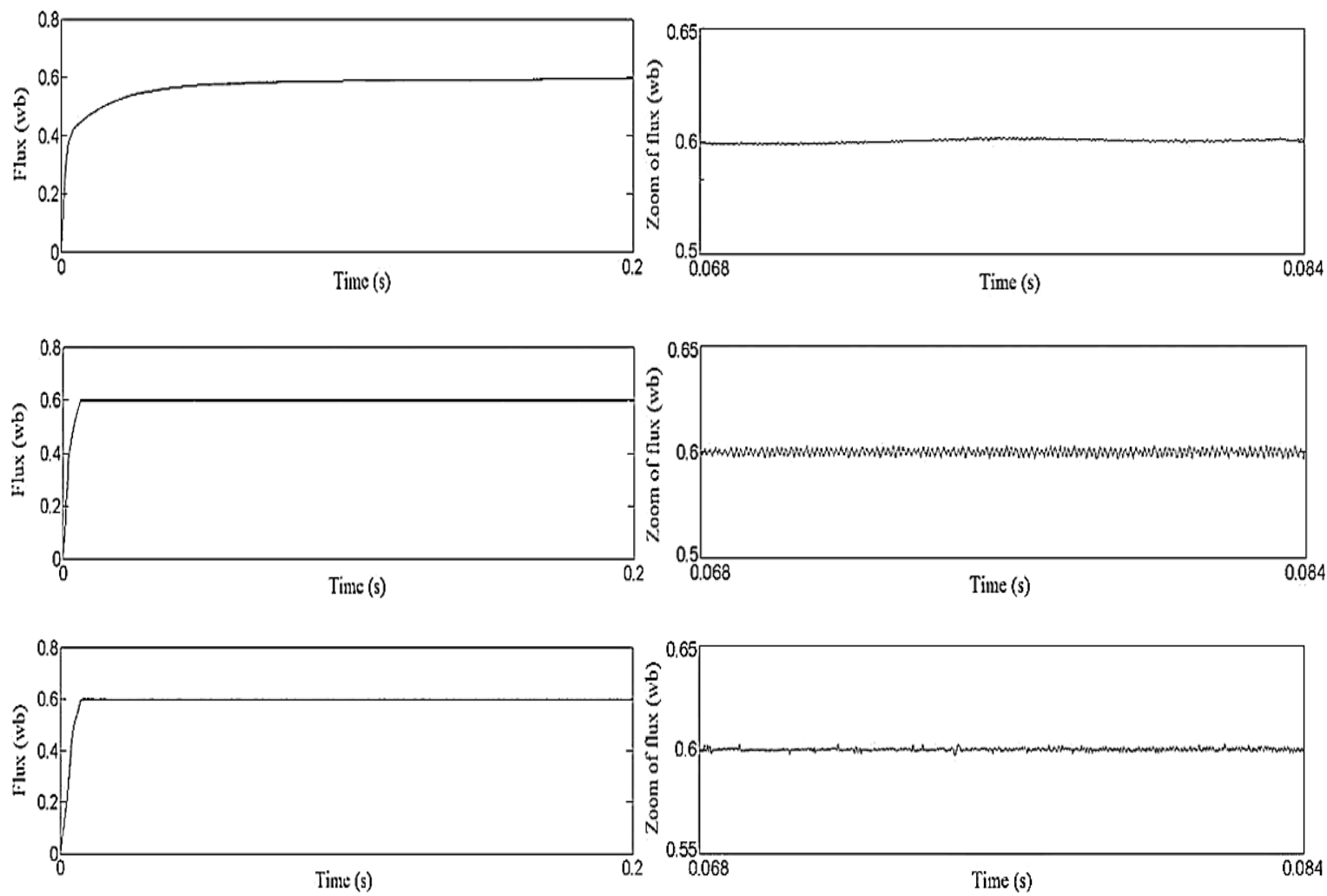

Figure 5. Simulation results of the stator flux response using vector control strategy, DTC method, and the proposed control strategy with GA; (a) vector control strategy, (b) DTC method, (c) proposed control strategy with GA 

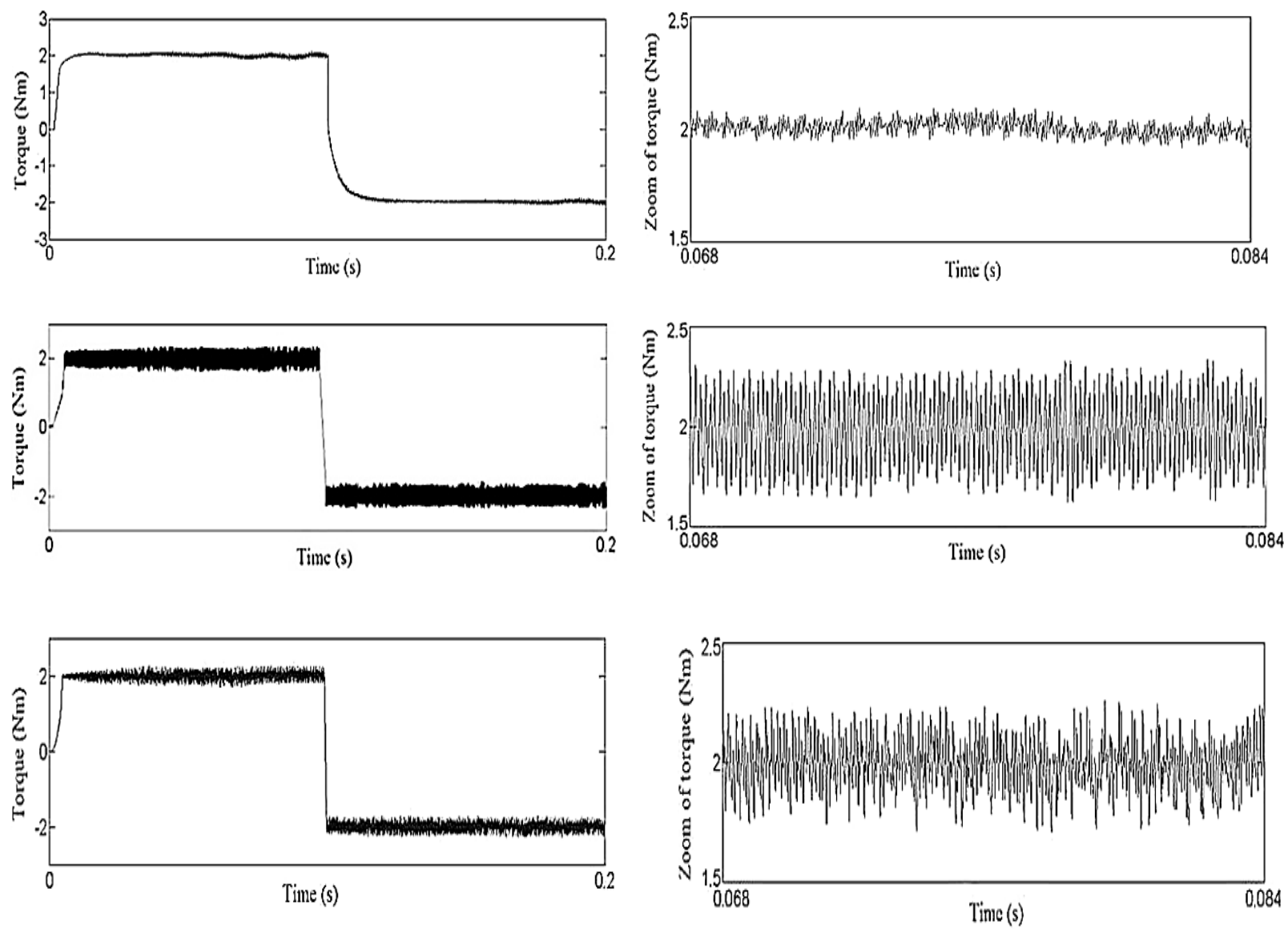

Figure 6. Simulation results of the torque response using vector control strategy, DTC method, and the proposed control strategy with GA; (a) vector control strategy, (b) DTC method, (c) proposed control strategy with GA

Figures 5 (c) and 6 (c) indicated that by using the proposed control method, flux and torque signals can track their reference values appropriately without any significant error. As can be seen from Figures 5 and 6 , the stator flux and torque signals of the vector control strategy, DTC method, and the proposed control strategy are almost the same, except for more ripples in the DTC method and fewer ripples in the vector control strategy. Moreover, the results confirm that the flux and torque responses under the introduced control system are faster than the DTC and vector control methods.

According to the simulation results of Figures 5 and 6, flux and torque ripples using the vector control method are almost $0.001 \mathrm{wb}$ and $0.05 \mathrm{Nm}$, respectively. Moreover, flux and torque ripples using the DTC method are almost $0.005 \mathrm{wb}$ and $0.6 \mathrm{Nm}$, respectively. In addition, flux and torque ripples using the proposed control method are almost $0.003 \mathrm{wb}$ and $0.3 \mathrm{Nm}$, respectively.

Furthermore, according to Figure 6, the time to reach steady state from $2 \mathrm{Nm}$ to $-2 \mathrm{Nm}$ using the vector control method, DTC technique, and proposed method is $8 \mu \mathrm{s}, 2 \mu \mathrm{s}$, and $0.16 \mu \mathrm{s}$, respectively.

The simulation results of Figures 5 and 6, indicated that the drive system performance under the introduced control method compared to the DTC method is better in both transient and steady state conditions. Additionally, the results indicate that the proposed method has faster dynamic response compared to the conventional vector control method. This is while the conventional vector control method has better accuracy. It is worth noting that the conventional vector control method is more complex than the proposed control method and it is very sensitive to the machine parameters and the coefficients of PI controllers. 
Figures 7 and 8, show the simulation results of proposed control method with and without the optimization of the coefficients of the PI controller (Figure 7 shows the simulation results of the flux response and Figure 8 shows the simulation results of the torque response). In Figures 7 and 8 , the reference stator flux is set to $0.6 \mathrm{wb}$. Moreover, the reference torque changes from $-3 \mathrm{Nm}$ to $3 \mathrm{Nm}$ at $\mathrm{t}=0.05 \mathrm{~s}$. In Figures 7 (a) and 8(a), the proportional coefficient and the integral coefficient are 100 and 2, respectively. Moreover, in Figures 7(b) and 8(b), the PI controller parameters are based on Table 3.
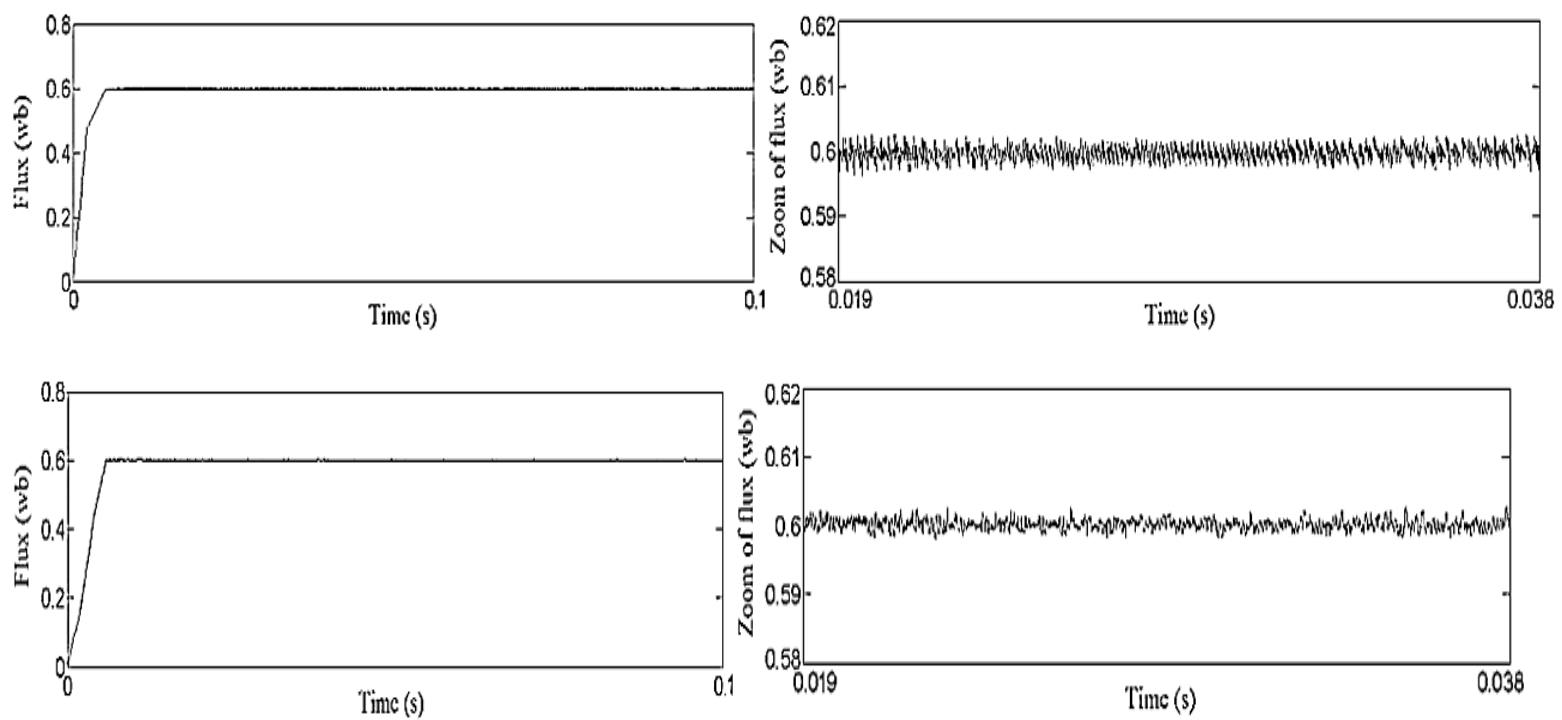

Figure 7. Simulation results of the stator flux response using the proposed control strategy with and without the optimization of the coefficients of the PI controller; (a) without optimization, (b) with optimization
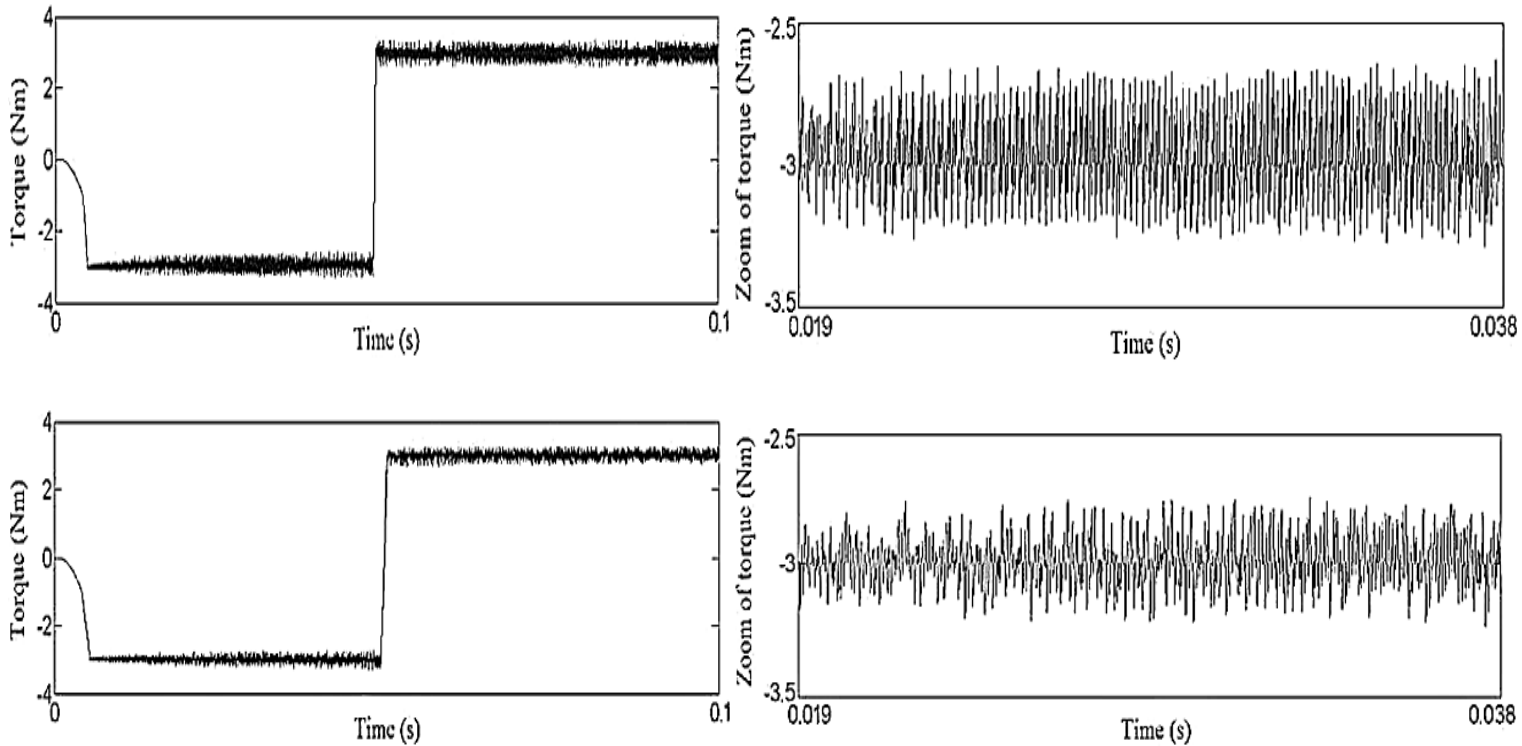

Figure 8. Simulation results of the torque response using the proposed control strategy with and without the optimization of the coefficients of the PI controller; (a) without optimization, (b) with optimization

As can be seen from Figures 7 and 8, both stator flux and torque signals are almost identical, except for further ripples in the proposed control method without optimization of the PI controller. 
In according to the simulation results of Figures 7 and 8, flux and torque ripples using the proposed control method without optimization of the PI controller are almost $0.006 \mathrm{wb}$ and $0.5 \mathrm{Nm}$, respectively, In addition, flux and torque ripples using the proposed control method with optimization of the PI controller are almost $0.003 \mathrm{wb}$ and $0.3 \mathrm{Nm}$, respectively.

\section{CONCLUSIONS}

In this paper, a novel hybrid DTC strategy based on predictive control for TPIM drives along with optimization of the PI controller using GA is presented. The hybrid control method is based on the conventional DTC method with optimal selection of voltage vectors based on the predictive control system. According to the simulations results, this hybrid control system significantly reduces flux and torque ripples and improves the dynamic response compared to the conventional DTC method. Additionally, the proposed method has a faster dynamic response compared to the conventional vector control method. Additionally, the comparison between the proposed method with and without the optimization of the coefficients of the PI controller indicates the effect of the PI controller optimization in the performance of the proposed hybrid control strategy.

\section{REFERENCES}

Amiri, M., Milimonfared, J., \& Khaburi, D. A. (2018). Predictive torque control implementation for induction motors based on discrete space vector modulation. IEEE Transactions on Industrial Electronics, 65(9), 6881-6889.

Beerten, J., Verveckken, J., \& Driesen, J. (2009). Predictive direct torque control for flux and torque ripple reduction. IEEE transactions on industrial electronics, 57(1), 404-412.

Berzoy, A., Rengifo, J., \& Mohammed, O. (2017). Fuzzy predictive DTC of induction machines with reduced torque ripple and high-performance operation. IEEE Transactions on Power Electronics, 33(3), 2580-2587.

Bolognani, S., Bolognani, S., Peretti, L., \& Zigliotto, M. (2008). Design and implementation of model predictive control for electrical motor drives. IEEE Transactions on industrial electronics, 56(6), 1925-1936.

de Almeida, A. T., Fong, J., Falkner, H., \& Bertoldi, P. (2017). Policy options to promote energy efficient electric motors and drives in the EU. Renewable and Sustainable Energy Reviews, 74, 1275-1286.

Demir, G., \& Vural, R. A. (2018, October). Speed Control Method Using Genetic Algorithm for Permanent Magnet Synchronous Motors. In 2018 6th International Conference on Control Engineering \& Information Technology (CEIT) (pp. 1-6). IEEE.

Ismail, H., Patkar, F., Jidin, A., Jidin, A. Z., Azlan, N. A. N., \& Sutikno, T. (2017). Constant Switching Frequency and Torque Ripple Minimization of DTC of Induction Motor Drives with Three-level NPC Inverter. International Journal of Power Electronics and Drive Systems, 8(3), 1035.

Jannati, M., Anbaran, S. A., Asgari, S. H., Goh, W. Y., Monadi, A., Aziz, M. J. A., \& Idris, N. R. N. (2017). A review on Variable Speed Control techniques for efficient control of Single-Phase Induction Motors: Evolution, classification, comparison. Renewable and Sustainable Energy Reviews, 75, 1306-1319.

Jannati, M., Anbaran, S., Zaheri, D. M., Idris, N. R. N., \& Aziz, M. J. A. (2013, December). A new speed sensorless SVM-DTC in induction motor by using EKF. In 2013 IEEE Student Conference on Research and Developement (pp. 94-99). IEEE.

Jannati, M., Monadi, A., Anbaran, S. A., Idris, N. R. N., \& Aziz, M. J. A. (2014). An exact model for rotor fieldoriented control of single-phase induction motors. TELKOMNIKA Indonesian Journal of Electrical Engineering, 12(7), 5110-5120. 
Jannati, M., Monadi, A., Yen, G. W., Asgari, S. H., Idris, N. R. N., \& Aziz, M. J. A. (2014, October). A simple vector control technique for 3-phase induction motor under open-phase fault based on GA for tuning of speed PI controller. In 2014 IEEE Conference on Energy Conversion (CENCON) (pp. 213-218). IEEE.

Jidin, A., Sim, N. L., \& Sutikno, T. (2017). Improvement of Torque Capability of Direct Torque Control of Induction Machines. International Journal of Power Electronics and Drive Systems, 8(3), 1070.

Kumar, R. H., Iqbal, A., \& Lenin, N. C. (2017). Review of recent advancements of direct torque control in induction motor drives-a decade of progress. IET Power Electronics, 11(1), 1-15.

Lin-Shi, X., Morel, F., Llor, A. M., Allard, B., \& Rétif, J. M. (2007). Implementation of hybrid control for motor drives. IEEE Transactions on Industrial Electronics, 54(4), 1946-1952.

Liu, C., \& Luo, Y. (2017). Overview of advanced control strategies for electric machines. Chinese Journal of Electrical Engineering, 3(2), 53-61.

Miranda, H., Cortés, P., Yuz, J. I., \& Rodríguez, J. (2009). Predictive torque control of induction machines based on state-space models. IEEE Transactions on Industrial Electronics, 56(6), 1916-1924.

Mossa, M. A., \& Bolognani, S. (2017, December). A new formulation of model predictive direct torque control for a sensorless IM drive. In 2017 Nineteenth International Middle East Power Systems Conference (MEPCON) (pp. 664670). IEEE.

Navardi, M. J., Milimonfared, J., \& Talebi, H. A. (2018). Torque and flux ripples minimization of permanent magnet synchronous motor by a predictive-based hybrid direct torque control. IEEE Journal of emerging and selected topics in power electronics, 6(4), 1662-1670.

Ouhrouche, M., Errouissi, R., Trzynadlowski, A. M., Tehrani, K. A., \& Benzaioua, A. (2016). A novel predictive direct torque controller for induction motor drives. IEEE Transactions on Industrial Electronics, 63(8), 5221-5230.

Papafotiou, G., Kley, J., Papadopoulos, K. G., Bohren, P., \& Morari, M. (2008). Model predictive direct torque control-Part II: Implementation and experimental evaluation. IEEE Transactions on industrial electronics, 56(6), 1906-1915.

Ramahlingam, S., Jidin, A., \& Sutikno, T. (2016). A Novel Optimal PI Parameter Tuning Strategy to Improve Constant Switching Performance of Direct Torque Control. International Journal of Power Electronics and Drive Systems, 7(2), 422.

Tabasian, R., Ghanbari, M., Esmaeli, A., \& Jannati, M. (2020). Control of three-phase induction machine drives during open-circuit fault: A review. IETE Journal of Research, 1-18.

Tarchała, G., \& Orłowska-Kowalska, T. (2018). Equivalent-signal-based sliding mode speed MRAS-type estimator for induction motor drive stable in the regenerating mode. IEEE Transactions on Industrial Electronics, 65(9), 69366947.

Vaez-Zadeh, S., \& Jalali, E. (2007). Combined vector control and direct torque control method for high performance induction motor drives. Energy conversion and management, 48(12), 3095-3101.

Vas, P. (1998). Sensorless vector and direct torque control. Oxford Univ. Press. 